\title{
RESPONSIBILITY AND ITS MANIFESTATION IN YOUTH PSYCHOLOGY
}

\section{NARGIZA SAGINDIKOVA}

Associate Professor, Karakalpak State University

\section{ABSTRACT}

Raises the idea that student self-governance is important in the development of a high level of responsibility. Hence, while responsibility is a key essential quality of any professional, if responsibility is not formed, he or she is a low-level professional. An irresponsible professional loses his professional dignity and the title of "expert". Therefore, while responsibility is the foundation on which a specialist is needed, it should be seen as a personal quality that elevates the specialist to a higher level.

The development of the moral aspects of the student's personality is confirmed by the following. First, the dynamics of several areas in the moral development of students are explored, the self-critical assessment of the individual enhances their moral qualities; moral self-esteem is gradually becoming a real behaviour.

Interpersonal relationships in the development of students' responsibility and, of course, their role in terms of their profession, their attitude to the task given to them by others (parents, teachers, adults), how he does it and feel how effective his result is for a student can to some extent lead to the formation of responsibility.

The formation of gender characteristics in young people contributes not only to their characteristics but also to the formation of a sense of responsibility, which is necessary for a person's behaviour. Gender roles also play an important role in the family, community, social environment, and educational activities.

In our study, the aspects of students' responsibility in their academic activities were studied. The results of the "Responsibility" test show the general situation of the manifestation of student's responsibility in educational activities, gender differences on almost every item.

KEYWORDS: Activity of Education, Problem-Solving Techniques, Psychological Peculiarities, Responsibility, Students' Psychology

Received: Jun 08, 2020; Accepted: Jun 28, 2020; Published: Sep 09, 2020; Paper Id.: IJMPERDJUN20201132

\section{INTRODUCTION}

One of the problems that require an in-depth study in psychology is responsibility. Some parts of this problem have been studied, from which Russian scientists have studied the importance of responsibility in labour activity, and the idea that they should focus on the development of a specific system of studying the responsibility of people in labour activity. Also, before studying the problem, the object studying the problem should be thoroughly studied, after which it is advisable to use problem-solving techniques. To study the importance of responsibility in the workplace, it is necessary to analyze the personal qualities and characteristics of workers, and then the main task in the process of studying personal responsibility - to identify the factors influencing the development of responsibility as a sustainable individual trait.

Surveys conducted abroad show that the formation of responsibility in educational activities affects the success of an individual in educational activities. Its lack of formation is the main reason for the failure of students 
in their academic activities and professional development. It also raises the idea that student self-governance is important in the development of a high level of responsibility. Hence, while responsibility is a key essential quality of any professional, if responsibility is not formed, he or she is a low-level professional. An irresponsible professional loses his professional dignity and the title of "expert". Therefore, while responsibility is the foundation on which a specialist is needed, it should be seen as a personal quality that elevates the specialist to a higher level.

If the locus of control determines the behaviour of a person in the events of his life strategy, it is also related to responsibility, because in any case a person is required to take responsibility for his attitude to the event and his behaviour during the event. It is possible to determine a person's responsibility through the locus of control.

The responsibility of the students is of course also felt in moral qualities. Psychologist V. A. Tokareva comes to such conclusions by studying the moral qualities and self-esteem characteristics of students. Among the main activities in the development of students' self-esteem are the qualities that are necessary for the system of interpersonal relationships, in establishing relationships with others. These qualities include responsibility, commitment, a sense of indebtedness, publicity, honesty, conscientiousness, mutual respect, humility, discipline, camaraderie, honesty, diligence, purposefulness, kindness, purposefulness, perseverance, demanding on oneself and others [5].

The analysis of the literature shows that the development of the moral aspects of the student's personality is confirmed by the following. First, the dynamics of several areas in the moral development of students are explored, the self-critical assessment of the individual enhances their moral qualities; moral self-esteem is gradually becoming a real behaviour. If in 1st-year students' abilities are associated with self-assessment, in the 4th year they adapt to real behaviour. In the research, the process of the moral development of students is compared with $1^{\text {st }}$ and $3^{\text {rd }}$-course students. Natural behavioural assessments and qualities increase the level of responsibility in their interpersonal relationships. The results of V. A. Tokareva's research also observed the formation and growth of moral norms in the activities and behaviour of students during their studies. It depends not only on the above qualities but also on principled news, respect for people, self and friendship, assertiveness in society, and generosity [5].

Young people are active not only in educational activities, but they are also more active in public affairs, especially in the field of technical innovations, they quickly learn new information. The assignments and directions given to them reflect their responsibility. In evaluating their performance, we need to build their self-confidence, which can be a motivation for their success in their future endeavours. A responsible person will succeed in his field.

\section{MATERIALS AND METHODS}

Interpersonal relationships in the development of students' responsibility and, of course, their role in terms of their profession, their attitude to the task given to them by others (parents, teachers, adults), how he does it and feel how effective his result is for a student can to some extent lead to the formation of responsibility.

The formation of gender characteristics in young people contributes not only to their characteristics but also to the formation of a sense of responsibility, which is necessary for a person's behaviour. Gender roles also play an important role in the family, community, social environment, and educational activities.

In our study, the aspects of students' responsibility in their academic activities were studied. The results of the "Responsibility" test show the general situation of the manifestation of student's responsibility in educational activities, gender differences on almost every item. 
According to the students' answers, in the general manifestation of responsibility, it was observed that the scale indicators, which represent some parameters and positions, are clearly expressed, some are partially expressed, and some are not expressed at all.

According to the overall results of the students, the scales of ergicity $(26,38)$, consciousness $(25,65)$, sthenia $(28,34)$ show the degree of a clear expression of responsibility; socio-centricity $(24,39)$, egocentricity $(20,27)$, objectivity $(24,45)$, subjective effectiveness $(21,06)$, internality $(24,10)$ and externality $(20,81)$ levels of situational manifestation of responsibility; It can be said that the low performance of the results of aergicity $(14,33)$, erudition $(15,39)$, asthenia $(15,03)$, on the contrary, expressed a state of responsibility. (Table 1.)

Table 1: Indicators of the Manifestation of Responsibility in Students

\begin{tabular}{|c|l|c|c|c|c|c|c|c|}
\hline \multirow{2}{*}{ No. Scales } & \multirow{2}{*}{} & Overall Results & \multicolumn{2}{c|}{ Girls } & \multicolumn{2}{c|}{ Boys } & \multirow{2}{*}{ t } \\
\cline { 3 - 8 } & & $\mathbf{M}$ & $\boldsymbol{\Sigma}$ & $\mathbf{M}$ & $\boldsymbol{\Sigma}$ & $\mathbf{M}$ & $\boldsymbol{\sigma}$ & \multirow{2}{*}{$-2,699 * *$} \\
\hline 1 & Ergicity & 26,38 & 6,29 & 25,42 & 6,21 & 27,35 & 6,25 & 1,272 \\
\hline 2 & Aergicity & 14,33 & 4,91 & 14,71 & 4,84 & 13,95 & 4,98 & $-1,356$ \\
\hline 3 & Sociocentricity & 24,39 & 5,31 & 23,94 & 5,24 & 24,85 & 5,37 & $-1,990^{*}$ \\
\hline 4 & Egocentricity & 20,27 & 5,37 & 21,04 & 5,16 & 19,51 & 5,50 & $-0,527$ \\
\hline 5 & Consciousness & 25,65 & 7,83 & 25,39 & 7,11 & 25,91 & 8,52 & $-0,056$ \\
\hline 6 & Erudition & 15,39 & 5,98 & 15,37 & 5,47 & 15,42 & 6,48 & 0,012 \\
\hline 7 & Objective effectiveness & 24,45 & 5,30 & 24,46 & 5,40 & 24,45 & 5,23 & $-1,676^{*}$ \\
\hline 8 & Subjective effectiveness & 21,06 & 5,32 & 20,46 & 5,29 & 21,66 & 5,31 & $-1,626$ \\
\hline 9 & Sthenia & 28,34 & 6,16 & 27,75 & 6,10 & 28,93 & 6,19 &, 193 \\
\hline 10 & Asthenia & 15,03 & 3,69 & 15,08 & 3,53 & 14,98 & 3,86 &,- 817 \\
\hline 11 & Internality & 24,10 & 4,81 & 23,84 & 5,38 & 24,37 & 4,17 & $-1,087$ \\
\hline 12 & Externality & 20,81 & 4,95 & 20,48 & 5,24 & 21,15 & 4,65 & \\
\hline
\end{tabular}

Based on the overall results of students' responsibility, the value of ergicity $(26,38)$ in educational activities shows that students are independent, ready to perform difficult tasks with a sense of responsibility in carrying out the tasks assigned to them; learning motivations, i.e. they have a comprehensive understanding of responsibility and a conscious attitude to carry out learning activities following their chosen profession (consciousness $(25,65)$ ). Besides, students have emotions that express a sense of pride in the performance of responsible tasks related to academic activities, as well as satisfaction with their work (sthenia $(28,34))$.

The situational manifestation of the position associated with certain social responsibilities in students shows that it is manifested on cognitive fronts (socio-centric $(24,39)$, egocentric $(20,27)$ ). It can be seen that the formation of social motives in students is a readiness for interpersonal relationships in the educational environment, based on the principle of mutual respect and esteem with others, the harmonization of their interests and the interests of others; means that the sociopsychological environment in the student group depends on a positive tone.

Students' regulatory, i.e., performance scales, the degree to which responsibilities are clearly expressed; objectivity $(24,45)$, subjective effectiveness $(21,06)$, internality $(24,10)$ and externality $(20,81)$ the level of situational manifestation of responsibility; aergicity $(14,33)$, erudition $(15,39)$, asthenia $(15,03)$, on the contrary, can be said to represent a state of manifestation of responsibility. The student period is a transition to the stage of maturity when in the process of professional training there is a need for self-determination, goal setting, the formation of complex professional skills and competencies. 
Our next task is to study gender differences in the average value of student responsibility. This is the second approach to interpreting values from experience.

Students had high, medium, and low levels in terms of responsibility in their gender differences.

According to the dynamics component, in the ergicity parameter, girls $(25,42)$ and boys $(27,35)$; in the emotional component, girls $(75,75)$ and boys $(28,93)$ showed high responsibility. However, in the ergicity parameters of girls and boys, there was a difference in the ratio of 1,95 for boys, and the difference in the reliability $(\mathrm{t}=-2.96 ; \mathrm{r} \leq 0.01)$ of the results was observed. This difference in reliability indicates that girls and boys have personal responsibility in their educational activities, developing the skills to prepare themselves for living independently. Although there were statistical differences as to gender differences in this regard, the dynamics of responsibility in student youth became a bit of a priority. A value reflecting the second statistical difference was found in the mean incidence of the subjects' cognitive components in the egocentric position. In this case, the reflection of the value between the conscious and knowledge in the understanding of responsibility by the student girls $(21,04)$ and the boys $(19,51)$ in the understanding of responsibility is 1.51 difference, $(\mathrm{t}$ $=-1.99 ; \mathrm{r} \leq 0.05)$ the reliability of the differences expressed. It is clear that in the process of performing certain tasks, the social nature of the responsibility of student girls and boys depends on the conditions and circumstances. It appears that student boys and girls prefer to take the situation into account when performing certain assigned social tasks. There is an increase in the student's responsibility for increasing self-confidence, fully realizing that independent learning and other social additional tasks and their performance, realizing that someone is demanding in the process of implementation.

Although this condition was relative, it prevailed in girls. Otherwise, the representatives of both social roles have a moderate level of responsibility.

The third case, in which gender differences reflected student responsibility based on statistical criteria, was observed in the reflexive assessment component, in which student boys $(21,66)$ and girls $(20,46)$ had a high degree of social responsibility ( $\mathrm{t}=-1.676 ; \mathrm{r} \leq 0.05$ ). Although the quantitative values are on the same level, the boys seem to prefer to achieve subjective results in imposing responsibility on the girls. This may be due to their perception that in their future careers, men will be responsible for women in family relationships.

There were no cases in which gender differences could be expressed in the remaining components representing the responsibility of the student. The method of correlation analysis was applied to get a detailed view of the quantitative indicators obtained from the experiment and their qualitative analysis. The following is an analysis of the correlation analysis of students' general and specific indicators of responsibility.

\section{RESULTS AND DISCUSSION}

It was observed that there are several important coefficients in the correlation between the quantitative indicators that reflect the responsibility of students. According to the general indicators of student responsibility, the increase in courage in the parameters of the components representing the dynamics, i.e. the decrease in irresponsibility due to the increase in students' sense of responsibility when loading complex tasks $(r=0.386 ; r \leq 0.01$ ); awareness of responsibility ( $r=0.432$; $\mathrm{r} \leq 0.01)$; deviation from theoretical considerations of responsibility $((\mathrm{r}=-0.336 ; \mathrm{r} \leq 0.01))$; satisfaction with the performance of responsible work $((\mathrm{r}=0.651 ; \mathrm{r} \leq 0.01))$; while control over the performance of responsible tasks leads to an increase in personal responsibility and self-assessment $((\mathrm{r}=0.158 ; \mathrm{r} \leq 0.05))$ and a decrease in the influence of others $((\mathrm{r}=-0.171$; $\mathrm{r} \leq 0.01)$ ). 
Conversely, when the dynamic component of responsibility in the learning process of students increases in the aergicity parameter, the desire to be in the community, society, people, motivation, a decrease in the priority of the community over their interests $(r=-0.339 ; r \leq 0.01)$; limitation to general aspects of responsibility $(r=0201 ; r \leq 0.01)$; decrease in sthenia $(r=-0,-0.246 ; r \leq 0.01)$ increase in asthenia $(r=0.368 ; r \leq 0.01)$; leading to a decrease in subjective control $(r=0.246 ; r \leq 0.01)$.

As a result of our research, we can say that the gender characteristics of responsibility in students' learning activities have similarities and differences in student boys and girls. The similarity aspect is the same in terms of the formation of responsibility, but in terms of level, it has slightly higher values in young men.

Based on the overall results of the students, it can be said that in all aspects of responsibility, 66 correlation values were not observed in all of them, but personality traits that play an important role in the formation of social responsibility in the educational process were observed.

\section{CONCLUSIONS}

There are relative similarities and differences between student boys and girls in the areas explained in our general analysis of the gender characteristics of student responsibility in academic activities. Although similarities were observed in the formation of responsibility in the same positions, it was typical to reflect slightly higher values in young men in terms of level. In the course of our research, we concluded that the consideration of gender characteristics of responsibility in the educational activities of students based on educational stages can also provide significant results.

\section{REFERENCES}

1. Bykov.S.V Socio-psychological regulation of personality responsibility. Diss. doc, psychology. Kazan-2006, pp. 37-38 (316, 27-29)

2. Course of the basics of gender research (chrestomathy). T.: Uzbekistan 2003. Moskovkiy tsentr gendernyx issledovaniy, 2000.

3. Lakshmi, A. K. "The selfie culture: Narcissism or counter hegemony." Journal of Communication and media Studies (2015).

4. Gavrilushkin S.A. Psychological specificity of personality responsibility manifestation among students with different patriotic orientation. Author's abstract. PhD in Psychology, Moscow: 2012, -S. 6

5. Gavrilushkin S. A. "Responsibility as a professional quality of an individual” Vector of science TSU. No. 1 (15), 2011. P.156159

6. Tokareva V.A. Psychology of moral development of a student's personality. T: Fan. 1989.S. 27

7. Setyanto, Yugih., Septia. Winduwati, and Lusia Savitri Setyo Utami. "Early Adolescent Behavior on Media Toward Idol Figure (Parasoial Study Preliminary Youth As An Effect of New Media)." International Journal of Communication and Media Studies (IJCMS) Vol 7 (2017).

8. Muzdybaev K. Psychology of responsibility - Leningrad, 1983, pp. 5 - 183.

9. Panarin. I.A. Psychology of social responsibility of leaders of youth movements. Diss.d.psychol.n. - M .: 2010.S. 39.41

10. Safaev N.S. Psychological features of students' understanding of national identity. Psychol.f. d. Diss. T. 2005, - 137b.

11. Brar, Sarvjeet Kaur. "Altruistic Behavior Among Adolescents in Relation to Their Emotional Maturity." International Journal of Educational Science and Research (IJESR) 7. 5, Oct 2017, 29-36 
12. Sagindikova N.Dj. Gender features of responsibility in student learning activities. - T .. «Science and technology», 2016, 120 $p$.

13. Sidorenko EV Methods of mathematical processing in psychology - SPb: Publishing house Rech, 2002, pp. 158 - 177.

14. Kabanova-Meller E.N. "Learning activities and developing learning. -M .: Knowledge, 1981, P.7

15. Kamenskaya. E.I. Social psychology. Phoenix, 2008.S. 55-56.

16. Brief psychological dictionary. Ed. A.V. Petrovsky. M .: 1985 . p. 124

17. Baruah, Himakshi, Pragaya Dashora, and Arti Parmar. "Impact of Cyberbullying on Psychological Health of Adolescents." International Journal of Humanities and Social Sciences (IJHSS) 6.4 (2017): 137-144.

18. Krylov L.V. author. Candidate of Pedagogy. Pedagogical conditions of education of social responsibility among university students. Kostroma 2010.p.10

19. Krupnov A.I., Pryadein V.P. Multidimensional functional analysis of responsibility // Methods of psychology. RPO Yearbook. T. 3. Issue 2. 1997. P. 147

20. Turgunov.Q Russian-Uzbek Glossary of Psychological Terms T; Teacher Publishing. 1975. B. 41 